\title{
Ocorrência de murcha bacteriana em helicônias e musácea ornamental no Distrito Federal
}

\author{
Débora M. Zoccoli ${ }^{1}$, Celso K. Tomita ${ }^{1,2}$ \& Carlos H. Uesugi ${ }^{1}$ \\ ${ }^{1}$ Departamento de Fitopatologia, Universidade de Brasília, 70910-900, Brasília, DF, Brasil; ${ }^{2}$ Mokiti Okada Association \\ Internacional, 72700-000, Brazlândia, DF, Brasil
}

Autor para correspondência: Carlos H. Uesugi, e-mail: uesugich@unb.br

\begin{abstract}
RESUMO
Plantas de Heliconia spp. e Musa spp. apresentando murcha foram observadas em plantio comercial no Distrito Federal. Testes laboratoriais e de inoculação confirmaram como sendo a bactéria Ralstonia solanacearum biovar 1 raça 2 responsável pela doença. Este é o primeiro relato da presença da bactéria em helicônia e musácea ornamental na região.
\end{abstract}

Palavras-chave: Ralstonia solanacearum raça 2, Heliconia spp., Musa spp., Moko.

\begin{abstract}
Occurrence of bacterial wilt in Heliconia and ornamental Musaceae in Federal District, Brazil

Plants of Heliconia spp. and Musa spp. presenting wilt were observed in commercial crops in Federal District, Brazil. Laboratory and inoculation tests confirmed the bacterium as Ralstonia solanacearum biovar 1 race 2 . This is the first report of bacterial wilt of heliconia and ornamental musaceae in this region.
\end{abstract}

Keywords: Ralstonia solanacearum race 2, Heliconia spp., Musa spp., Moko disease.

O Moko causado por Ralstonia solanacearum (Smith) Yabuuchi et al. raça 2 é uma das principais doenças bacterianas da bananeira e helicônia, está presente em vários países como: Belize, Brasil, Colômbia, Costa Rica, Equador, El Salvador, Granada, Guatemala, Guiana, Honduras, Jamaica, México, Nicarágua, Panamá, Peru, Suriname, Trinidad e Tobago, EUA, Venezuela nas Américas; Etiópia, Líbia, Malawi, Nigéria, Senegal na África e Índia, Filipinas, Indonésia, Malásia, Tailândia e Vietnam na Ásia (OEPP/ EPPO, 2006). No Brasil a bactéria é considerada praga quarentenária A2 (restrita aos estados do Amapá, Amazonas, Pará, Pernambuco, Rondônia, Roraima e Sergipe) (MAPA - Instrução Normativa $N^{\circ} 52$ de 20/11/2007; Coelho Neto et al., 2004; Lins \& Coelho, 2004). A bactéria causadora da doença pode ser disseminada por mudas, ferramentas infectadas, contato raiz-raiz, do solo para raiz ou por insetos que visitam inflorescência, tais como as vespas (Polybia spp.), mosca-das-frutas (Drosophyla spp.) e abelhas (Trigona spp.) (Cordeiro \& Kimati, 1997).

No Distrito Federal, a demanda por plantas ornamentais tem aumentado devido à expansão populacional, acarretando o aumento da área cultivada, bem como a introdução de novas culturas e a criação do pólo de flores. As helicônias e musáceas ornamentais estão entre as espécies introduzidas, por meio de mudas de diferentes variedades provenientes de várias regiões do país, inclusive do Norte (Belém) e de procedência desconhecida, trazendo consigo vários problemas fitossanitários. A murcha bacteriana (Moko) é um exemplo de introdução através de mudas e tem sido uma das bacterioses mais destrutivas de diversas espécies vegetais, dentre as famílias de solanáceas, musáceas e heliconiáceas (Hayward, 1991).

Plantas de helicônias (Heliconia bihai e $H$. psittacorum cv. Red Gold) e musacea ornamental (Musa coccinea) apresentando sintomas de murcha das folhas internas do pseudocaule, progredindo para morte e comprometimento de toda touceira (Figura 1A) têm sido observadas, em pequenas reboleiras, em áreas de plantio comercial, nas regiões dos Núcleos Rurais Rajadinha e Alexandre Gusmão no Distrito Federal. Pseudocaules apresentavam intenso escurecimento da região interna central com exsudação típica de pus bacteriano (Figura 1B).

A bactéria isolada em meio de cultura 523 (Kado \& Heskett, 1970) apresentou características fluída e branca, Gram negativa, OF oxidativo, oxidase positiva, não utilizando nenhum dos seguintes carboidratos (manitol, sorbitol, dulcitol, maltose, lactose, celobiose), confirmando ser o agente patogênico Ralstonia solanacearum biovar 1 . Plantas de Heliconia bihai e H. psittacorum cv. Red Gold, musácea ornamental (Musa coccinea) bem como bananeiras do grupo nanicão (Musa spp. AAA) e prata (Musa spp. AAB), tomate (Solanum lycopersicum) variedade Santa Clara e fumo (Nicotiana tabacum) foram inoculadas em 

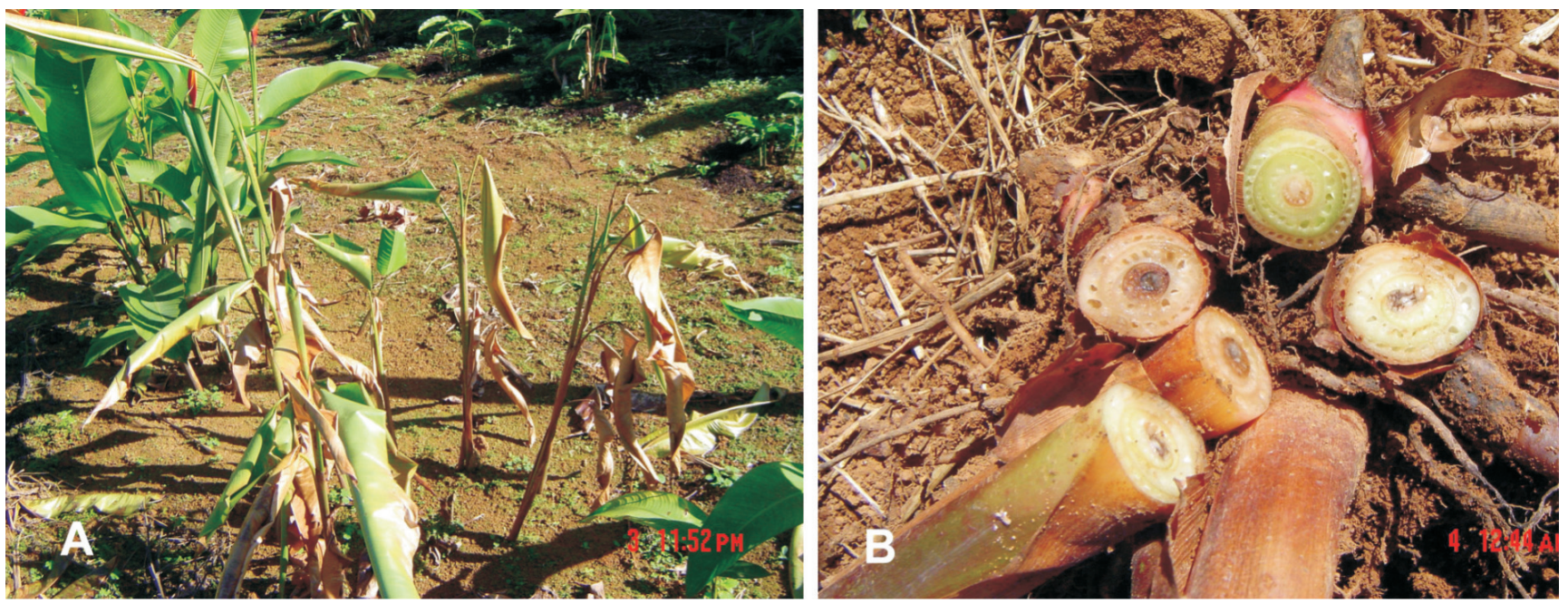

FIGURA 1 - A. Sintoma de murcha em Heliconia psittacorum cv. Red Gold no campo. B. Escurecimento da parte central do pseudocaule e exsudação de pus bacteriano.

plantas distintas, com aplicação de suspensão bacteriana de aproximadamente $1 \times 10^{8} \mathrm{ufc} / \mathrm{mL}$, obtida de cultura fluída branca/rosea em meio TTC (triphenyl tetrazolium chloride) (Kelman, 1954), diretamente no solo ou com o auxílio de uma seringa aplicada no pseudocaule. Os testes de inoculação realizados em casa de vegetação foram positivos em banana prata, helicônia, musácea ornamental e fumo (reação de hipersensibilidade) e negativos para banana variedade nanica e no tomate, determinando como sendo a bactéria da raça 2, provavelmente a estirpe $\mathrm{H}$ (helicônia) (French \& Sequeira, 1970), sendo este o primeiro relato em musácea ornamental e helicônias no Distrito Federal, Brasil.

Sendo uma doença quarentenária, as plantas afetadas foram erradicadas e as áreas onde as plantas se encontravam alqueivadas. Segundo Cordeiro \& Kimati (1997), as medidas de controle podem variar dependendo da situação. Caso a doença ainda não tenha entrado, a exclusão é recomendada. Quando a doença já esteja presente, recomenda-se a erradicação e medidas profiláticas como mudas sadias, desinfestação de ferramentas utilizadas na capina, desbaste, desfolha, corte de coração, colheita e eliminar o coração que é um atrativo para insetos visitadores de inflorescência. Até o presente momento não foi observado dano econômico em nenhuma das propriedades. Dois isolados de uma propriedade estão preservados na Coleção de Bactérias Fitopatogênicas do Departamento de Fitopatologia da Universidade de Brasília.

\section{REFERÊNCIAS BIBLIOGRÁFICAS}

Coelho Neto RA, Pereira BG, Noda H, Boher B (2004) Murcha bacteriana no Estado do Amazonas, Brasil. Fitopatologia Brasileira 29:21-27.

Cordeiro ZJM, Kimati H (1997) Doenças da Bananeira (Musa spp.). In: Kimati H, Amorim L, Bergamin Filho A, Camargo LEA, Rezende JAM (Eds.) Manual de Fitopatologia. Vol. 2. Doenças das Plantas Cultivadas. $4^{\mathrm{a}}$ Ed. São Paulo SP. Ceres. pp. 112 -136.

French ER, Sequeira L (1970) Strains of Pseudomonas solanacearum from Central and South America: a comparative study. Phytopathology 60:506-512.

Hayward AC (1991) Biology and epidemiology of bacterial wilt caused by Pseudomonas solanacearum. Annual Review of Phytopathology 29:65-87.

Kado CI, Heskett MG (1970) Selective media for isolation of Agrobacterium, Corynebacterium, Erwinia, Pseudomonas and Xanthomonas. Phytopathology 60:969-979.

Kelman A(1954) The relationship of pathogenicity in Pseudomonas solanacearum to colony appearance on a tetrazolium medium. Phytopathology 44:693-695.

Lins SRO, Coelho RSB (2004) Ocorrência de doenças em plantas ornamentais tropicais no Estado de Pernambuco. Fitopatologia Brasileira 29:332-335.

MAPA. Instrução Normativa N ${ }^{\circ}$ 52. (20/11/2007). http://extranet. agricultura.gov.br/sislegis-consulta/consultarLegislação.do (4 de abril de 2008).

OEPP/EPPO (2006). Distribution Maps of Quarantine Pests for Europe. Ralstonia solanacearum race 2. http://pqr.eppo.org/datas/ PSDMS2/PSDMS2.pdf. (01 de dezembro de 2008) 